\title{
Evaluation of Blockchain Business Success Factors Using AHP
}

\author{
Seoyeon Park \\ Department of Computer Science and Engineering, Chung-Ang University, \\ 84 Heukseok-ro, Dongjak-gu, Seoul, 06974, Korea \\ tjsdus1354@gmail.com \\ http://www.cau.ac.kr \\ Jiyun Kim \\ Department of Food and Nutrition, Sahmyook University, \\ 815 Hwarang-ro, Nowon-gu, Seoul, 01795, Korea \\ wldbs3592@naver.com \\ http://www.syu.ac.kr \\ Dukshin Oh \\ Department of Management Information Systems, Sahmyook University, \\ 815 Hwarang-ro, Nowon-gu, Seoul, 01795, Korea \\ ohds@syu.ac.kr \\ http://www.syu.ac.kr \\ Jongwan Kim* \\ Smith College of Liberal Arts, Sahmyook University, \\ 815 Hwarang-ro, Nowon-gu, Seoul, 01795, Korea \\ kimj@syu.ac.kr \\ http://www.syu.ac.kr
}

\begin{abstract}
Blockchain is a distributed digital ledger technology that is used in various business fields to record and store transaction information. Additionally, blockchain provides its own method of verification. There is a need to establish a business model based on identified success factors for blockchain technology so this technology can thrive as a business tool. However, many companies have difficulty identifying the business success factors of blockchain technology. In this paper, we intend to provide a means of motivating blockchain technology development and user growth by analyzing the factors required for blockchain to be successful in business. Blockchain success factors for businesses were extracted from literature reviews and a survey of experts, professionals, and general users in related fields. We verified the survey results based on the consistency of responses using the analytic hierarchy process. The analysis results for the success factors of blockchain revealed that cryptography $(0.2828)$, transparency (0.1244), and key management $(0.1228)$ were selected as the main success factors. The analysis results for the critical success factors of blockchain identified in this study are expected to enable decision-makers to support sustainable business models and investment strategies.
\end{abstract}

Keywords: Blockchain; Critical Success Factors; Analytic Hierarchy Process; Multiple Criteria Decision Making.

\section{Introduction}

Blockchain is a distributed digital ledger technology that jointly verifies, records, and stores transaction information using peer to peer ( $\mathrm{P} 2 \mathrm{P})$ methods [1]. Blockchain is currently used in various fields, including transaction-related settlements, contracts, and information records, and across many different platforms. Blockchain is a research hotspot that is being expanded into new business technologies based on its excellent reliability [22]. Blockchain has realized secure and reliable transactions based on consensus in decentralized P2P networks over the past decade. The security and trustworthiness of blockchain have the potential to grow while guaranteeing the safety of authenticated access during the fourth industrial revolution, where almost all transactions will be conducted over the internet.

The current application fields of blockchain are described in the following paragraphs.

First, it has been used in the area of financial transactions [18] as a technological and industrial innovation in the financial technology industry [28]. This is a novel application that has fundamentally changed the

${ }^{*}$ Corresponding author. 
conventional financial and economic operating model.

In the healthcare sector, timestamps are printed on each drug produced to prevent drug counterfeiting in the pharmaceutical industry [17]. These timestamps are used to detect the origins of products and components, and to clarify ownership transfer through blockchain.

In the education sector, class certificates can be issued without third-party intervention or identity verification by applying blockchain.

In transportation, blockchain is used to eliminate expensive charges stemming from the benefits provided to service users by transportation companies [14]. In e-commerce, blockchain is widely used because entire transactions can be traced transparently without a broker using distributed ledgers [16]. In e-government [19], blockchain is used to build trust between governments and multiple companies, and to integrate resources from multiple companies into a single platform using a consensus mechanism.

Financial transactions based on user authentication are essential factors for consideration in various areas. When verifying user identity in blockchain, the strength of cryptographic technology using hashing functions and asymmetric keys, as shown in Fig. 1 [10], is directly linked to the reliability of financial transactions conducted by authenticated users.

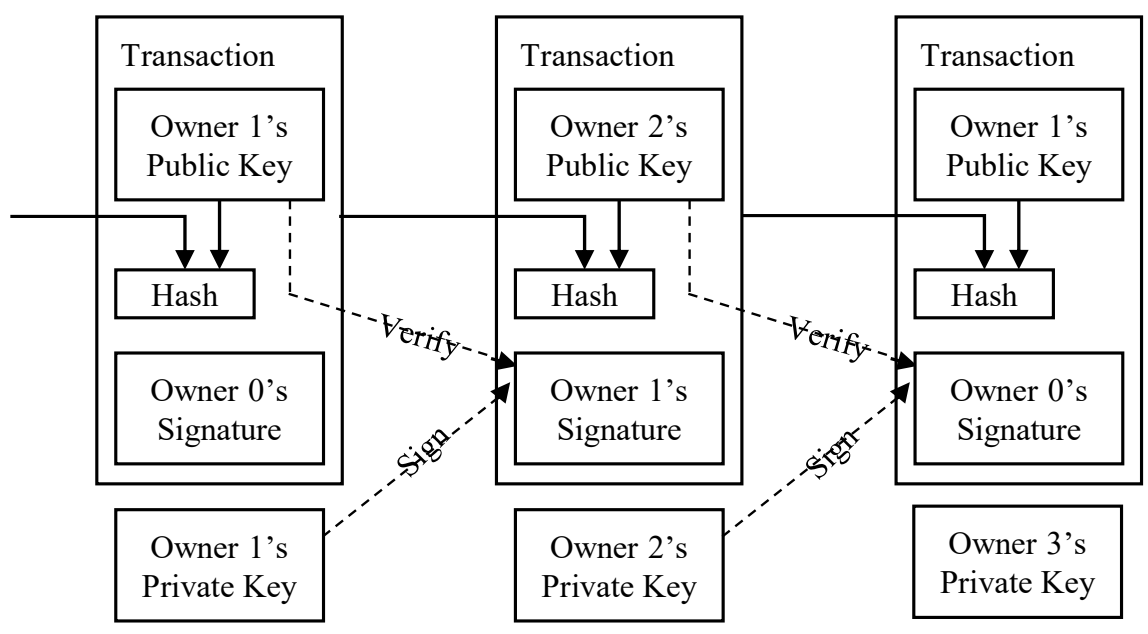

Fig. 1. Blockchain-individual blocks.

Strategic models are contained in the business models of companies and are directly linked to the success of businesses. Blockchain can facilitate "sustainable business success" [21]. Business sustainability is achievable through appropriate decision making based on customer needs from the perspective of a sound business environment, economy, and society [29]. An effective strategic model considering these factors can be translated into sustainable revenue generation. In other words, when establishing a business strategy model, enabling users to leverage blockchain content efficiently is a key factor in sustaining the continued success of a business.

For a business model to be established as a strategic pattern, the success factors of strategic models must be considered. Therefore, decision makers must attempt to identify the factors of success of strategic models and determine how to reflect these factors in a business model. The establishment of a strategic model is performed to increase the sustainability of a business and can be accomplished by analyzing user requirements.

Users have various expectations regarding the characteristics of a product or technology and businesses must make decisions to meet such user expectations.

New technology, such as blockchain, can have a significant social and business ripple effect. Various applications have been implemented to enhance business success. However, it is difficult to secure the success of a business by stressing only the application of new technology without sufficient analysis of user requirements.

For these reasons, it is critical to analyze the success factors of blockchain technology. However, to date, there have been few papers that have analyzed the success factors of blockchain from a strategic perspective for businesses. This indicates that sustainable strategic models for blockchain technology are in the early stages of development.

In this study, we extracted the characteristics of blockchain through a literature review of blockchain technology and evaluated these characteristics using the analytic hierarchy process (AHP), which is a multicriteria decision-making method (MCDM) [30, 31]. 
The process of evaluating the success factors of blockchain began with analyzing the business model structure of enterprises and hierarchical structures to identify the characteristics and key elements of blockchain technology through a literature review. Next, a pairwise comparison questionnaire on blockchain characteristics was prepared to investigate the level of user requirements for technical characteristics. Consistency was verified for the investigated characteristics by using the AHP and the success factors for technology were identified by assigning weights and priorities to different characteristics.

In this paper, we aim to provide a basis for extracting success factors for this new technology, and to establish strategic models for enterprises by analyzing the characteristics of blockchain based on user requirements.

The remainder of this paper is organized as follows. Chapter 2 introduces a business model and research related on the application of blockchain technology. It also describes 11 characteristics of blockchain extracted from existing literature. Chapter 3 describes the preprocessing of the AHP for evaluating multiple characteristics. Chapter 4 analyzes the major success factors of blockchain based on the AHP evaluation and suggests decision making directions for businesses. Chapter 5 concludes this paper with a discussion of the implications of the main characteristics of blockchain.

\section{Research Study}

\subsection{Business model}

Critical success factors (CSFs) are closely related to the strategic business model of an enterprise [26]. A robust business model always considers CSFs as key elements of business operations. The general definition of a business model for an entire industry is a milestone for the profitability of enterprises [25]. A general business model is defined by the operational methods of enterprises, customer requirements, customer values, and enterprise performance [24]. The various factors of business strategy should be included in the structure of a business model, whose goal is to represent a business framework. Because businesses deal with different forms of frameworks, business model factors have been defined differently by many researchers. Therefore, it is essential to identify the success factors of a given technology when identifying business model factors.

\subsection{Application of blockchain technology}

Blockchain is based on distributed ledger technology [27], where a ledger is distributed across multiple nodes or computing devices. Blockchain uses cryptographic algorithms (Merkle tree and hashing functions) that consist of transactions, blocks, and chains. A transaction is the smallest unit of work and it exchanges the entire ledger between nodes. A block consists of a header and a long list of transactions. All nodes in the system maintain a long blockchain and are connected. Nodes can be protected from tampering by applying cryptographic technology. The block (completion history) + chain (complete verification) = timestamp relationship represents a coupled structure that provides an immutable and integrated database [13].

Blockchain technology has recently been successfully integrated into existing operations in various fields, demonstrating its flexibility in many applications [14]. Additionally, the development of various coin platforms, exchanges, and blockchain-based development platforms has demonstrated the marketability of blockchain, as well as the scalability of active blockchain networks in multiple areas [13].

\subsection{Blockchain attributes}

The attributes of blockchain are defined slightly differently in each study, and the business model framework of businesses varies depending on the business field. Therefore, it is not possible to apply various characteristics indiscriminately.

The blockchain terminology dictionary [19], which is being prepared by Paolo Tasca and Claudio Tessone (2018) [9], is a project for evaluating the consistency of terminology used in blockchain technology. The integration of terminology for both attributes and blockchain technology is still underway. The blockchain terminology dictionary defines terms that are similar or have mixed use among related literature, providing a single definition for identifying the characteristics of blockchain technology.

In this study, when preprocessing and extracting attributes, we identified the definitions of related attributes by extracting attributes from the literature and applying blockchain terminology dictionary definitions.

It can help clarify terminology in evaluations when a definition is provided when conducting a user survey on the main attributes of blockchain. Therefore, we included an attribute definition table in our questionnaire. Because respondents who were not directly involved in computer science were included in the survey, we also defined the attributes of blockchain explicitly, as shown in Table 1. 
In Table 1, the upper level in the left column lists the decision criteria for the AHP hierarchy diagram presented in Fig. 2. These criteria are followed by the blockchain characteristics, a synonym list for each characteristic, definition that describes characteristic in familiar words, and corresponding reference literature for each definition. We obtained synonyms by extracting all of the terms used in various papers and summarizing them into four evaluation criteria and eleven alternative attributes. There are eleven factors for the blockchain business model: decentralization, P2P networking, transparency, immutability, anonymity, smart contracts, cryptography, key management, scalability, extensibility, and interoperability. The meaning of each characteristic is described briefly in the following subsections.

\subsubsection{Decentralization}

Decentralization refers to reducing authentication management costs and latency by removing the role of a central certificate authority (CA) by facilitating direct connections between users. The verification process for transaction processing typically goes through trusted CAs (e.g., banking systems), thereby incurring administrative costs, such as transaction fees, resulting in high costs and low performance based on increased processing time introduced by CAs [19]. Blockchain does not require a trusted third party because it uses a P2P system between trusted peers.

\subsubsection{P2P network}

A P2P network refers to a blockchain network in which interconnected blockchain users (peers) send and receive transaction data directly to each other [11]. A blockchain is maintained by collaboration between individual participants connected to the network without authoritative central organizations, agencies, or institutions for processing, recording, or managing transactions.

\subsubsection{Transparency}

Transparency indicates that the content, including transactions, of all blocks in a blockchain are made public to all blockchain nodes. Data stored in blockchains are copied and distributed to all nodes connected to the network [9].

\subsubsection{Immutability}

Immutability indicates that no transactions in a block registered in the blockchain network can be modified or deleted. This means that a history of records in which transactions are recorded persists indefinitely. The ledger cannot be modified without permission unless an individual or group of individuals controls the majority of "voters." Voter control occurs when there is a single group that controls at least $51 \%$ of the total computing power [12].

\subsubsection{Anonymity}

Anonymity refers to keeping the real identity of a block creator secret. Based on the anonymity of blockchain, interactions in a network are performed by using public keys for the nodes in a blockchain network [19]. Although all bitcoin transactions are transparent, they do not contain any information regarding the traders, meaning they maintain anonymity.

\subsubsection{Smart contract}

A smart contract refers to a processing system in which the contract content of a transaction is embedded in advance, meaning the transaction corresponding to the contract is automatically processed when the transaction history is recorded in a block. A smart contract automatically executes contract content when predefined conditions are met by preparing contracts using digital instructions. Because a contract result is clear according to the predefined conditions, it is used as a stored procedure that is called when a transaction occurs. Smart contracts are more convenient compared to traditional methods for changing access rights for transactions and policies. Smart contracts are implemented in Ethereum using the Solidity programming language [15]. Additionally, Hyperledger Fabric uses a smart contract called Chaincode.

\subsubsection{Cryptography}

Cryptography refers to strengthening the associations between blocks by recording fixed-length data (hashes) for a previous block in the next block whenever a block is continuously connected. A hashing function and asymmetric key are adopted by the series of cryptographic processes, which initiate a cryptographic function [23]. The security model for blockchain assumes the availability of public-key cryptography. 
Table 1. Blockchain Characteristics and Simple Definitions

\begin{tabular}{|c|c|c|c|c|}
\hline $\begin{array}{l}\text { Upper } \\
\text { level }\end{array}$ & Characteristics & Synonyms & Definition & $\begin{array}{c}\text { Reference } \\
\text { Literature for } \\
\text { Definition }\end{array}$ \\
\hline \multirow{4}{*}{ Trustless } & 1. Decentralization & $\begin{array}{l}\text { Disintermediate } \\
\text { d Same rights }\end{array}$ & $\begin{array}{l}\text { Reducing authentication management } \\
\text { costs and latency by removing the } \\
\text { role of a central CA by facilitating } \\
\text { direct connections between users. }\end{array}$ & $\begin{array}{l}\text { Sultan et al. } \\
\text { 2019[19] }\end{array}$ \\
\hline & 2. P2P network & - & $\begin{array}{l}\text { A blockchain network in which } \\
\text { interconnected blockchain users } \\
\text { (peers) send and receive transaction } \\
\text { data directly. }\end{array}$ & $\begin{array}{l}\text { Yang et al. } \\
2019 \text { [13] }\end{array}$ \\
\hline & 3. Transparency & - & $\begin{array}{l}\text { The contents, including transactions } \\
\text { of all blocks in the blockchain are } \\
\text { made public to all blockchain nodes. }\end{array}$ & $\begin{array}{l}\text { Lin and Tzu- } \\
\text { Chun } 2017 \\
\text { [12] }\end{array}$ \\
\hline & 4. Immutability & Persistency & $\begin{array}{l}\text { Any transaction in a block registered } \\
\text { in the blockchain network cannot be } \\
\text { modified or deleted. }\end{array}$ & $\begin{array}{l}\text { Zheng et al. } \\
2018 \text { [11] }\end{array}$ \\
\hline \multirow[b]{2}{*}{$\begin{array}{l}\text { Transacti } \\
\text { on } \\
\text { Preserva } \\
\text { bility }\end{array}$} & 5. Anonymity & $\begin{array}{l}\text { Identity } \\
\text { Untraceable }\end{array}$ & $\begin{array}{l}\text { Keeping the real identity of a block } \\
\text { creator secret. }\end{array}$ & $\begin{array}{l}\text { Lin and Tzu- } \\
\text { Chun } 2017 \\
{[12]}\end{array}$ \\
\hline & $\begin{array}{l}\text { 6. Smart } \\
\text { Contract }\end{array}$ & - & $\begin{array}{l}\text { Putting a processing system in place } \\
\text { in which the contract content of a } \\
\text { transaction is embedded in advance, } \\
\text { meaning the transaction } \\
\text { corresponding to the contract is } \\
\text { automatically processed when the } \\
\text { transaction history is recorded in the } \\
\text { block. }\end{array}$ & $\begin{array}{l}\text { Dinh et al. } \\
2018[8]\end{array}$ \\
\hline \multirow[t]{2}{*}{ Security } & 7. Cryptography & $\begin{array}{l}\text { Privacy } \\
\text { Encryption }\end{array}$ & $\begin{array}{l}\text { Strengthening the association } \\
\text { between blocks by recording fixed- } \\
\text { length data (hashes) from the } \\
\text { previous block in the next block } \\
\text { whenever a block is continuously } \\
\text { connected. }\end{array}$ & $\begin{array}{l}\text { Nakamoto } \\
2008[10]\end{array}$ \\
\hline & $\begin{array}{l}\text { 8. Key } \\
\text { management }\end{array}$ & Safety & $\begin{array}{l}\text { Enabling the safe use of keys through } \\
\text { the smooth operation of wallets. } \\
\text { (Wallet: an address for easily creating } \\
\text { and managing cryptographic keys). }\end{array}$ & $\begin{array}{l}\text { Bonneau et al. } \\
\text { 2015[3] }\end{array}$ \\
\hline \multirow{3}{*}{$\begin{array}{l}\text { Growth } \\
\text { Potential }\end{array}$} & 9. Scalability & $\begin{array}{l}\text { More } \\
\text { Addressing } \\
\text { Space }\end{array}$ & $\begin{array}{l}\text { The ability to optimize storage space } \\
\text { by processing large volumes of } \\
\text { transactions promptly. }\end{array}$ & $\begin{array}{l}\text { Zheng et al. } \\
2018 \text { [11], } \\
\text { Lyons et al. } \\
{[21]}\end{array}$ \\
\hline & 10. Extensibility & & $\begin{array}{l}\text { The blockchain length grows as new } \\
\text { blocks are added. }\end{array}$ & $\begin{array}{l}\text { Tasca et al. } \\
2018[9]\end{array}$ \\
\hline & 11. Interoperability & Compatibility & $\begin{array}{l}\text { Even blockchains with different } \\
\text { platforms are compatible with each } \\
\text { other when using standardized open } \\
\text { protocols. }\end{array}$ & $\begin{array}{l}\text { Tasca et al. } \\
2018[9], \\
\text { Tschorsch et } \\
\text { al. } 2016[20]\end{array}$ \\
\hline
\end{tabular}




\subsubsection{Key management}

Key management means that the smooth operation of a wallet (key pool) enables the safe use of keys. Here, a wallet is an address book for easily creating and managing cryptographic keys. To strengthen key management, users can store keys on their own devices, protect their wallets with a password, use offline storage, or expose only transaction signing functions by separating key information from host devices using a hardware security module called Air Gap [3].

\subsubsection{Scalability}

Scalability refers to the ability to optimize storage space by processing large volumes of transactions promptly. Scalability can be improved by limiting the number of records in a transaction, the number of users on a public blockchain, or the number of nodes connected to the network [9].

\subsubsection{Extensibility}

Extensibility means that the blockchain length grows as new blocks are added. A greater blockchain length represents an increase in the number certified blocks, which increases the trustworthiness of blockchain.

\subsubsection{Interoperability}

Interoperability means that blockchains on different platforms are compatible with each other through standardized open protocols. Interoperability determines the future ecosystem of the blockchain network and the integration and compatibility of various blockchain technologies or blockchain-related technologies [9, 21].

\subsection{Stratification of decision-making factors}

\section{AHP Preprocessing}

Before investigating the attributes of blockchain, we first divided the problems necessary for decision making into a hierarchical structure and developed a schema. At the top layer of the hierarchy is a single final goal. At the middle layer of the hierarchy are the decision-making criteria and stratified dependency relationships. Finally, at the lowest layer of the hierarchy are alternatives and multiple evaluation items that can be related to one level of evaluation, which form an overall hierarchical structure. A hierarchical diagram of this process is presented in Fig. 2. The final goal is blockchain business success and the evaluation criteria are trustworthiness, transaction preservability, security, and growth potential. Alternatives are composed of decentralization, P2P networks, transparency, immutability, anonymity, smart contracts, cryptography, key management, scalability, extensibility, and interoperability.



Fig. 2. AHP decision tree of blockchain characteristics.

The papers selected as the schema for extracting blockchain characteristics were chosen from global 
conferences and journals. We selected a total of nine basic blockchain papers, as shown in Table 2. The reasons for selecting these papers can be summarized as follows. Sultan et al. [19] defined the characteristics of blockchain in the same manner used in our paper and Kapsammer et al. (2018) [2] attempted to organize keywords for blockchain papers using universal markup language (UML) because the organization of UML is helpful for extraction [35]. The papers from Bonneau et al. (2015) [3] to Tasca and Tessone (2018) [9] correspond to the papers selected by Kapsammer et al. [2].

Table 2. Blockchain Literature’s Basic Information

\begin{tabular}{|c|c|c|c|}
\hline Refs & Literature Name & Extracted Blockchain characteristics List & $\begin{array}{l}\text { Literature } \\
\text { Scale }\end{array}$ \\
\hline [19] & $\begin{array}{l}\text { IOT Security Issues Via } \\
\text { Blockchain: A Review } \\
\text { Paper }\end{array}$ & $\begin{array}{l}\text { Decentralization, P2P Network, Transparency, } \\
\text { Immutability, Anonymity, Smart Contract, } \\
\text { Cryptography, Scalability }\end{array}$ & $\begin{array}{c}\text { ACM } \\
\text { Conference }\end{array}$ \\
\hline$[2]$ & $\begin{array}{l}\text { The Blockchain Muddle : A } \\
\text { Bird's-Eye View on } \\
\text { Blockchain Surveys }\end{array}$ & $\begin{array}{l}\text { Decentralization, Cryptography, Key management, } \\
\text { Scalability, Extensibility }\end{array}$ & $\begin{array}{c}\mathrm{ACM} \\
\text { Conference }\end{array}$ \\
\hline$[3]$ & $\begin{array}{l}\text { SoK : Research } \\
\text { Perspectives and } \\
\text { Challenges for Bitcoin and } \\
\text { Cryptocurrencies }\end{array}$ & $\begin{array}{l}\text { Decentralization, P2P Network, Immutability, } \\
\text { Anonymity, Smart Contract, Cryptography, Key } \\
\text { management, Interoperability }\end{array}$ & $\begin{array}{l}\text { IEEE } \\
\text { Conference }\end{array}$ \\
\hline$[4]$ & $\begin{array}{l}\text { A taxonomy of blockchain- } \\
\text { based systems for } \\
\text { architecture design. }\end{array}$ & $\begin{array}{l}\text { Decentralization, P2P Network, Transparency, } \\
\text { Immutability, Anonymity, Smart Contract, } \\
\text { Cryptography, Key management, Scalability, } \\
\text { Interoperability }\end{array}$ & $\begin{array}{l}\text { IEEE } \\
\text { Conference }\end{array}$ \\
\hline$[5]$ & $\begin{array}{l}\text { Technical Analysis of } \\
\text { Established Blockchain } \\
\text { Systems }\end{array}$ & $\begin{array}{l}\text { Decentralization, P2P Network, Transparency, } \\
\text { Immutability, Anonymity, Smart Contract, } \\
\text { Cryptography, Key management, Scalability, } \\
\text { Extensibility, Interoperability }\end{array}$ & $\begin{array}{l}\text { Master's } \\
\text { Thesis }\end{array}$ \\
\hline$[6]$ & $\begin{array}{l}\text { A Comprehensive } \\
\text { Reference Model for } \\
\text { Blockchain-based } \\
\text { Distributed Ledger } \\
\text { Technology }\end{array}$ & $\begin{array}{l}\text { Immutability, Anonymity, Smart Contract, } \\
\text { Cryptography, Scalability }\end{array}$ & Conference \\
\hline$[7]$ & $\begin{array}{l}\text { Understanding the } \\
\text { blockchain using enterprise } \\
\text { ontology }\end{array}$ & $\begin{array}{l}\text { Decentralization, Transparency, Immutability, } \\
\text { Anonymity, Smart Contract, Cryptography, } \\
\text { Scalability }\end{array}$ & Conference \\
\hline$[8]$ & $\begin{array}{l}\text { Untangling blockchain: A } \\
\text { data processing view of } \\
\text { blockchain systems }\end{array}$ & $\begin{array}{l}\text { Decentralization, P2P Network, Transparency, } \\
\text { Smart Contract, Cryptography, Key management, } \\
\text { Scalability }\end{array}$ & IEEE Journal \\
\hline$[9]$ & $\begin{array}{l}\text { Ontology of Blockchain } \\
\text { Technologies. Principles of } \\
\text { identification and } \\
\text { classification }\end{array}$ & $\begin{array}{l}\text { Decentralization, Cryptography, Scalability, } \\
\text { Extensibility, Interoperability }\end{array}$ & $\begin{array}{c}\text { Elsevier } \\
\text { Journal }\end{array}$ \\
\hline
\end{tabular}

\subsection{Setting of importance and consistency based on the pairwise comparison of characteristics}

The importance of the factors at each level for the pairwise comparison of characteristics were determined as follows. First, the factors at each level were paired and one-to-one relative evaluations were performed by using the relationship factors from the level above as evaluation criteria. The pairwise comparisons return the values listed in Table 3. When the number of comparison factors is $\mathrm{n}$, decision makers perform $n(n-1) / 2$ pairwise comparisons.

Next, according to the pairwise comparison results, the importance values of the attributes at each level and a pairwise comparison matrix are calculated. Simultaneously, the consistency of the pairwise comparisons is calculated in the form of a consistency index (CI). Importance and the $\mathrm{CI}$ were calculated by applying the eigenvalue method to the pairwise comparison matrix. For reviewing the pairwise comparisons when the $\mathrm{CI}$ is 
not satisfactory (0.1-0.15 or more), sufficient consistency can be secured through the recalculation of pairwise comparisons based on the differences between the first pairwise comparison matrix and an inverted pairwise comparison matrix.

Table 3. Importance scale for AHP

\begin{tabular}{|c|c|}
\hline Selection & Evaluation Value \\
\hline Extremely Important & 9 \\
\hline Very Important & 7 \\
\hline Important & 5 \\
\hline Moderately Important & 3 \\
\hline Similarly Important (Equal importance) & 1 \\
\hline
\end{tabular}

The CI is calculated based on the maximum value of the eigenvalues $(\lambda)$ in each row sorted by priority. The CI defined by Saaty [30] is shown in Eq. (1).

$$
a_{t j}=\left(1+\delta_{t j}\right) w_{t} / w_{i}
$$

There are cases in which it may be reasonable to convert the CI into recalculated values based on the processing of incomplete pairwise comparison information. CI recalculation is performed for objective weight combinations to recalculate reference weights and combine subjective and target weights after obtaining weight estimates from an expert group [34].

Normalization is performed to estimate the relative weight (w: weight) of each matrix factor by of finding the eigenvalue $(\lambda)$ in the comparison matrix $\mathrm{A}$, which contains the pairwise comparison results. These weights are used to determine the priority of each factor. For the weight $w_{t j}$ in the comparison matrix A, if A following normalization is a matrix with complete consistency, meaning the factor $a_{t j}$ in A has a value of $w_{i} / w_{j}$, then $a_{t j} \times a_{t k}=a_{t k}$ must hold true. This means that if $\mathrm{i}$ is considered to be $\mathrm{x}$ times more important than $\mathrm{j}$ and $\mathrm{j}$ is considered to be y times more important than $\mathrm{k}$, then i should be evaluated to be $x \times y$ times more important than $\mathrm{k}$. However, there is a need to verify the degree of logical consistency in matrix A because such consistency is difficult to maintain in actual responses [32]. Consistency uses the condition of $\lambda_{\max }>n$ if complete consistency is not maintained for the responses to pairwise comparisons [33]. An estimate $a_{t j}$ of the importance of factor $i$ to relative factor $j$, which is the target of pairwise comparison, can be defined as follows:

However, $\delta_{t j}$ must be $\delta_{t j}>-1$ as the degree of discrepancy for $w_{t} / w_{j}$.

Here, the difference between the maximum eigenvalue $\lambda_{\max }$ obtained from the observed pairwise comparison matrix and maximum eigenvalue $\mathrm{n}$ of the pairwise comparison matrix with complete consistency is expressed as follows:

$$
\lambda_{\max }-n=\frac{1}{n}
$$

The differences between the maximum $\mathrm{n}$ values of the pairwise contrast matrix must have perfect coherence. In the equation above, if the estimate $a_{t j}$ exactly matches $w_{t} / w_{j}$, then $\delta_{t j}=0$ and $\lambda_{\max }-n=\mathrm{c}$ hold. Therefore, it is assumed that consistent judgment is made by an evaluator when the ${ }^{\lambda} \max$ value of the pairwise comparison matrix is close to $\mathrm{n}$, meaning we can define the $\mathrm{CI}$ as follows:

$$
C I=\frac{\lambda_{\max }-\tau}{n-1} \text {. }
$$

As the maximum eigenvalue, $\lambda_{\max }$ in Eq. (3) represents the maximum value among the eigenvalues of each item, where $\mathrm{n}$ is the number of attributes in the comparison matrix.

When calculating the consistency ratio (CR) in AHP, it is necessary to use the average random index, as shown in Eq. (4). The CR indicates whether or not decision maker evaluations are made randomly. The CR should be in the range of $0<=\mathrm{CR}<1$. The closer the $\mathrm{CR}$ is to zero, the greater the consistency of responses. In general, if the CR value is less than 0.1 (i.e., within 10\%) it is assumed that the results of the pairwise comparisons in the AHP are reliable. Some studies in the social science field have allowed CRs as high as 0.2 (20\%) by considering that it is difficult to secure independence between high and low criteria based on the nature of questionnaires. Therefore, in this study, we allowed CIs as high as 0.2 to reduce the number of missing data when calculating incomplete pairwise comparisons. 


$$
C R=\frac{C l}{R i}
$$

\subsection{Calculation of priority}

Priority means that the target for aggregation is selected based on the hierarchical structure and calculated by multiplying the alternative values obtained from each evaluation criterion by the evaluation criteria value obtained from the final goal.

The relative priority centered around the weight is represented by a one-dimensional priority vector, as shown in Eq. (5).

$$
\text { Relative priority }\left(w_{1}\right)=\left(\Sigma w_{1 f}\right) / n_{1} \quad(j=1,2, \ldots n) \text {. }
$$

The scoring of each evaluation item for the evaluation target is conducted based on the priority and can be used as effective information for determining the final business model for a company to analyze.

\section{Evaluation}

\subsection{Respondent evaluation}

The questionnaire, which was conducted to develop evaluation guidelines for the proposed blockchain success factors, was distributed by sending a shortened URL for a Google questionnaire via the simple notification service. As shown in Fig. 3, the AHP decision hierarchy was used to perform calculations in the AHP software Super Decisions. Because we used Super Decisions, the mathematical formula for the eigenvalue method is not described in detail. Fig. 4 presents a flowchart representing the procedure for solving the AHP decision making problem.

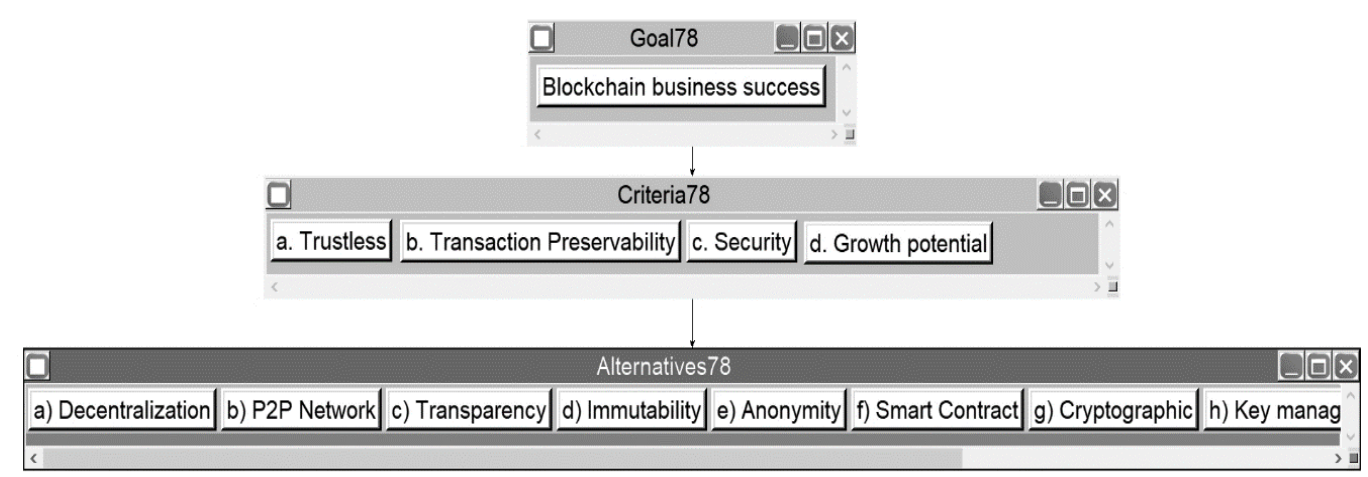

Fig. 3. AHP decision tree in Super Decisions.

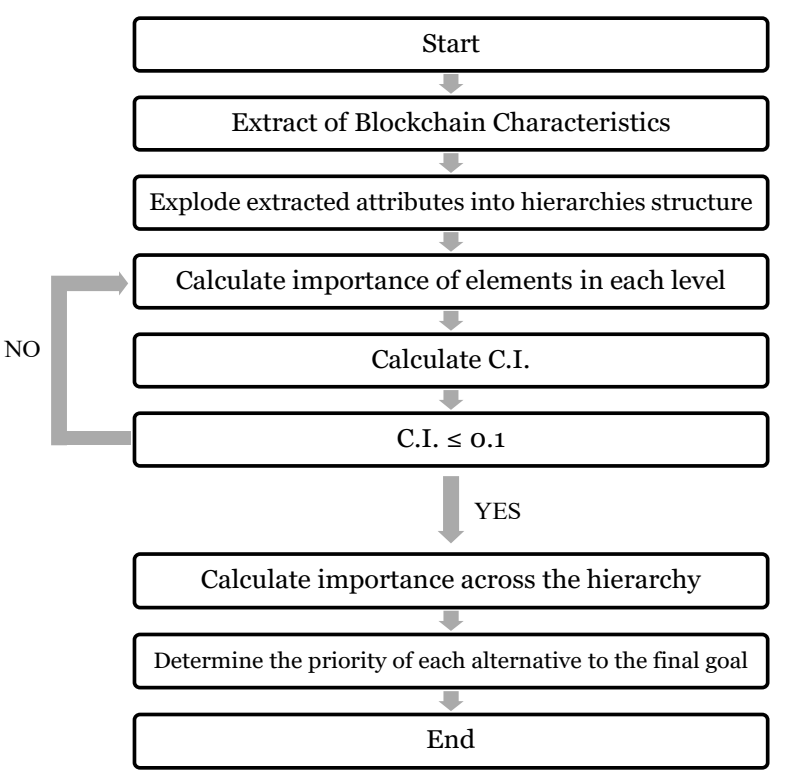

Fig. 4. AHP execution order flowchart. 
To investigate the characteristics of the survey respondents, we included questions regarding each respondent's interest in computer science and their occupations at the beginning of the questionnaire. The question regarding interest in computer science was used as an indicator of whether or not survey respondents had experience using blockchain (regardless of their field) based on the nature of user accessibility in blockchain applications. In particular, for the group that responded that they were interested in computer science, this question indicated that they are potential contributors to blockchain development and planning in their field. The question regarding the occupations of the respondents was included because respondents with various occupations could become more interested in blockchain when taking the survey. These two questions indicated that we did not have to investigate additional characteristics based on the presence of a reasonable respondent base.

Fig. 5 and Fig. 6 presents the classification results for the respondent characteristics described above. These results indicate that the calculation results for the AHP respondent dataset should provide reliable information.

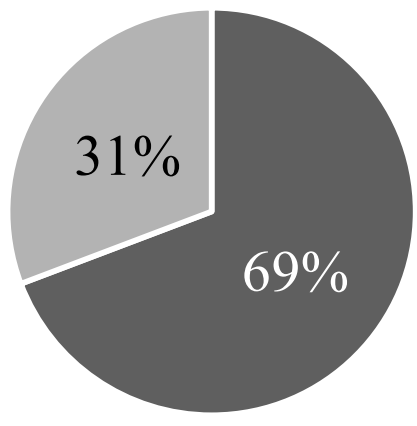

- interested in computer science : 54 people

- not interested in computer science : 24 people

Fig. 5. Measure of interest in computer science.

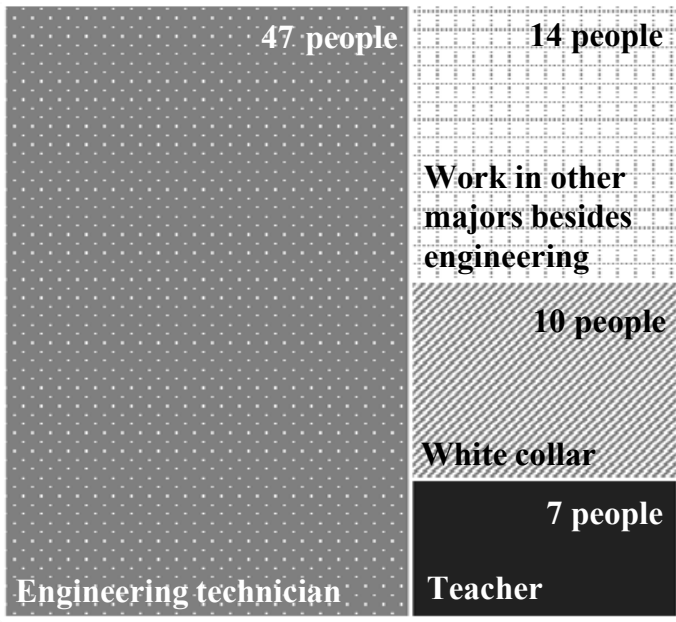

\section{Engineering \\ technician \\ Work in other majors \\ besides engineering}

White collar

- Teacher

Fig. 6. Respondent job types.

The survey was conducted on four occupational groups that were divided into engineering technicians (computer science majors, students in graduate schools for computer science, and blockchain software developers), those pursuing careers in majors other than engineering (majors in other studies or enrolled in graduate schools for other studies), white-collar workers, and education-related workers (teachers or professors).

The survey revealed that the engineering technician group was the largest occupational group with 47 people. Sixteen of these people were involved in blockchain software development. The blockchain professionals who responded to the survey worked in various business fields of blockchain software, such as software development, software planning, system operations, and system management. 


\subsection{Relative priority and consistency evaluation of evaluation items}

The process of calculating the results of the eigenvalue method using Super Decisions for the relative priority of the 78th respondent is presented in Fig. 7. W refers to the weight value and subscripts such as $G$ and $C a$ for each weight refer to the goal criteria. The criteria labels refer to the criteria listed in Table 4. Each matrix refers to the sub-factors in Fig. 2. For example, the $W_{C a}$ matrix in Fig. 7 represents the weights of decentralization, P2P network, transparency, and immutability.

Table 4. Summary of AHP weights, priorities, and CRs with software-calculated results

\begin{tabular}{|c|c|c|c|c|c|c|c|c|}
\hline \multirow[b]{2}{*}{ Criteria } & \multirow[b]{2}{*}{ Weights } & \multirow[b]{2}{*}{ Ranks } & \multirow[b]{2}{*}{ Alternatives } & \multirow[b]{2}{*}{ Weights } & \multirow{2}{*}{$\begin{array}{c}\text { Geometric } \\
\text { mean }\end{array}$} & \multirow{2}{*}{$\begin{array}{l}\text { Whole } \\
\text { Ranks }\end{array}$} & \multicolumn{2}{|c|}{$\mathbf{C R}$} \\
\hline & & & & & & & $\begin{array}{c}\text { Alter- } \\
\text { natives }\end{array}$ & Criteria \\
\hline \multirow[t]{4}{*}{ Trustless } & \multirow[t]{4}{*}{0.3285} & \multirow[t]{4}{*}{2} & Decentralization & 0.1975 & 0.0649 & 7 & \multirow{4}{*}{0.0096} & \multirow{11}{*}{0.0091} \\
\hline & & & P2P Network & 0.1105 & 0.0363 & 10 & & \\
\hline & & & Transparency & 0.3786 & 0.1244 & 2 & & \\
\hline & & & Immutability & 0.3135 & 0.1030 & 4 & & \\
\hline \multirow[t]{2}{*}{ Transaction } & \multirow[t]{2}{*}{0.1564} & \multirow[t]{2}{*}{3} & Anonymity & 0.4689 & 0.0733 & 6 & \multirow{2}{*}{0.0000} & \\
\hline & & & Smart Contract & 0.5311 & 0.0831 & 5 & & \\
\hline \multirow[t]{2}{*}{ Security } & \multirow[t]{2}{*}{0.4056} & \multirow[t]{2}{*}{1} & Cryptography & 0.6972 & 0.2828 & 1 & \multirow[b]{2}{*}{0.0000} & \\
\hline & & & $\begin{array}{c}\text { Key } \\
\text { management }\end{array}$ & 0.3028 & 0.1228 & 3 & & \\
\hline \multirow{3}{*}{$\begin{array}{l}\text { Growth } \\
\text { Potential }\end{array}$} & \multirow[t]{3}{*}{0.1095} & \multirow[t]{3}{*}{4} & Scalability & 0.3474 & 0.0381 & 9 & \multirow{3}{*}{0.0717} & \\
\hline & & & Extensibility & 0.2168 & 0.0237 & 11 & & \\
\hline & & & Interoperability & 0.4358 & 0.0477 & 8 & & \\
\hline
\end{tabular}

$$
\begin{aligned}
& W_{G}=(0.1581,0.1581,0.5437,0.1401) \\
& W_{C a}=(0.2689,0.0521,0.5457,0.1333) \\
& W_{C b}=(0.25,0.75) \\
& W_{C c}=(0.9,0.1) \\
& W_{C d}=(0.3442,0.0671,0.5887)
\end{aligned}
$$

Fig. 7. $78^{\text {th }}$ Respondent: all hierarchy weights and priorities.

\subsubsection{Eigenvalue method}

W refers to the weight value and subscripts such as $G$ and $C a$ for each weight refer to the goal criteria. The criteria labels refer to the criteria listed in Table 4. Each matrix refers to the sub-factors in Fig. 2. For example, $\mathrm{Ca}\left(\lambda_{\max }-n\right)$ in Fig. 8 indicates "the maximum eigenvalue order of the comparison matrix" for the first criterion, namely Criterion a.

$$
\begin{gathered}
G\left(\lambda_{\text {max }}-n\right)=0.0329 \\
C_{a}\left(\lambda_{\text {max }}-n\right)=0.0896 \\
C_{b}\left(\lambda_{\text {max }}-n\right)=0.0000 \\
C_{c}\left(\lambda_{\text {max }}-n\right)=0.0000 \\
C_{d}\left(\lambda_{\text {max }}-n\right)=-1.2729
\end{gathered}
$$

Fig. 8. $78^{\text {th }}$ Respondent eigenvalue method recalculation values.

\subsubsection{Evaluation of the $C R$}

Recalculation results with complete consistency are presented in Fig. 9.

$$
\begin{aligned}
& C R_{G}=0.0109, \\
& C R_{C a}=0.0299, C R_{C b}=0.0000, C R_{C c}=0.0000, C R_{C d}=0.0678
\end{aligned}
$$

Fig. 9. $78^{\text {th }}$ Respondent all hierarchy CRs. 


\subsubsection{Evaluation of relative priorities and consistency of evaluation items}

In Table 4, we listed the weight and priority for each criterion, weight and priority for each alternative, and the $\mathrm{CR}$ of the criteria and alternatives for all 78 responses.

\section{Conclusion}

Predicting success when developing blockchain applications or platforms has become a crucial issue in blockchain-related businesses. Because blockchain technology is applied to various types of content in the real world, marketers are paying significant attention to the success factors of blockchain content. Identifying success measures to guide marketers based on information obtained from success factor analysis is now a common interest in blockchain businesses.

In this study, we aimed to identify customer-oriented functions in blockchain applications and success factors that enhance corporate identity in terms of business practices by understanding the value of blockchain based on the analysis and evaluation of customer preference factors.

To achieve this, a survey was conducted and the results were evaluated according to the AHP technique proposed by Saaty [30]. In this paper, we only analyzed the results of one survey based on space limitations. The final CR, which was calculated as the arithmetic mean of all survey results, was 0.0091 , indicating excellent evaluation consistency.

When evaluating the success factors of blockchain using the AHP, the main priorities were determined to be cryptography, transparency, and key management. This means that development companies starting new businesses should consider improving the security of blockchain more intensively beyond the function of coin trading. Furthermore, given the fact that the priorities of cryptography, transparency, and key management are high in blockchain technology with various application ranges, relieving user anxiety regarding blockchain technology must be considered to achieve the sustainable use of such technology.

In this study, we examined the characteristics of blockchain according to research literature published by many scholars. A survey was conducted to evaluate these characteristics by selecting participants using blockchain in the real world. Therefore, our evaluation results represent a basis for the identification of not only success factors, but also information and communication technology content trends based on the potential for ever-changing blockchains.

\section{Acknowledgments}

This paper was supported by the National Research Foundation of Korea (NRF) Grant funded by the Korea Government (Ministry of Education) [NRF-2017R1D1A1B03035884, NRF-2018R1D1A1B07045642].

\section{References}

[1] Hou, H. (2017). The application of blockchain technology in E-government in China. In 2017 26th International Conference on Computer Communication and Networks (ICCCN) pp. 1-4. IEEE.

[2] Kapsammer, E.; Pröll, B.; Retschitzegger, W.; Schwinger, W., Weißenbek, M.; Schönböck, J. (2018). The Blockchain Muddle: A Bird's-Eye View on Blockchain Surveys. In Proceedings of the 20th International Conference on Information Integration and Webbased Applications \& Services pp. 370-374.

[3] Bonneau, J.; Miller, A.; Clark, J.; Narayanan, A.; Kroll, J. A.; Felten, E. W. (2015). Sok: Research perspectives and challenges for bitcoin and cryptocurrencies. In 2015 IEEE Symposium on Security and Privacy pp. 104-121. IEEE.

[4] Xu, X.; Weber, I.; Staples, M.; Zhu, L.; Bosch, J.; Bass, L.; ... Rimba, P. (2017). A taxonomy of blockchain-based systems for architecture design. In 2017 IEEE International Conference on Software Architecture (ICSA) pp. 243-252. IEEE.

[5] Haffke, F. (2017). Technical Analysis of Established Blockchain Systems. Master's thesis. Technical University of Munich, SW Engineering for Business Informatics.

[6] Ellervee, A.; Matulevicius, R.; Mayer, N. (2017). A Comprehensive Reference Model for Blockchain-based Distributed Ledger Technology. In ER Forum/Demos pp. 306-319.

[7] De Kruijff, J.; Weigand, H. (2017). Understanding the blockchain using enterprise ontology. In International Conference on Advanced Information Systems Engineering pp. 29-43. Springer, Cham.

[8] Dinh, T. T. A.; Liu, R.; Zhang, M.; Chen, G.; Ooi, B. C.; Wang, J. (2018). Untangling blockchain: A data processing view of blockchain systems. IEEE Transactions on Knowledge and Data Engineering, 30(7), 1366-1385.

[9] Tasca, P.; Thanabalasingham, T.; Tessone, C. J. (2017). Ontology of blockchain technologies. Principles of identification and classification. SSRN Electronic Journal, 10.

[10] Nakamoto, S. (2019). Bitcoin: A peer-to-peer electronic cash system. Manubot.

[11] Zheng, Z.; Xie, S.; Dai, H. N.; Chen, X.; Wang, H. (2018). Blockchain challenges and opportunities: A survey. International Journal of Web and Grid Services, 14(4), pp. 352-375.

[12] Lin, I. C.; Liao, T. C. (2017). A Survey of Blockchain Security Issues and Challenges. IJ Network Security, 19(5), pp. 653-659.

[13] Yang, W.; Aghasian, E.; Garg, S.; Herbert, D.; Disiuta, L.; Kang, B. (2019). A Survey on Blockchain-Based Internet Service Architecture: Requirements, Challenges, Trends, and Future. IEEE Access, 7, pp. 75845-75872.

[14] Duy, P. T.; Hien, D. T. T.; Hien, D. H.; Pham, V. H. (2018). A survey on opportunities and challenges of Blockchain technology adoption for revolutionary innovation. In Proceedings of the Ninth International Symposium on Information and Communication Technology pp. 200-207.

[15] Seokgi, K.; Seungyeol, K.; Dohui, J. (2018). IT trend special report. hanbit media. Inc.

[16] Böhme, R.; Christin, N.; Edelman, B; Moore, T. (2015). Bitcoin: Economics, technology, and governance. Journal of economic Perspectives, 29(2), pp. 213-238. 
[17] Mettler, M. (2016). Blockchain technology in healthcare: The revolution starts here. In 2016 IEEE 18th international conference on ehealth networking, applications and services (Healthcom) pp. 1-3. IEEE.

[18] Fanning, K.; Centers, D. P. (2016). Blockchain and its coming impact on financial services. Journal of Corporate Accounting \& Finance, 27(5), pp. 53-57.

[19] Sultan, A.; Mushtaq, M. A.; Abubakar, M. (2019). IOT Security Issues Via Blockchain: A Review Paper. In Proceedings of the 2019 International Conference on Blockchain Technology pp. 60-65.

[20]

[21] Tschorsch, F. Scheuermann, B. (2016). Bitcoin and beyond: A technical survey on decentralized digital currencies. IEEE Communications Surveys \& Tutorials, 18(3), pp. 2084-2123.

[22] Lyons, T. (2018). EU Blockchain Observatory and Forum. In Workshop Report. Government Services and Digital Identity. Brussels, July 5.

[23] Fischer, C. D. (2017). The Blockchain Buzz. JOURNAL OF GOVERNMENT FINANCIAL MANAGEMENT.

[24] Wang, W.; Hoang, D. T.; Hu, P.; Xiong, Z.; Niyato, D.; Wang, P.; ... Kim, D. I. (2019). A survey on consensus mechanisms and mining strategy management in blockchain networks. IEEE Access, 7, pp. 22328-22370.

[25] Chen, M. K.; Wang, S. C. (2010). The critical factors of success for information service industry in developing international market: Using analytic hierarchy process (AHP) approach. Expert Systems with Applications, 37(1), pp. 694-704.

[26] Krishnamurthy, S. (2003). E-commerce management, text and cases, Thompson learning.

[27] Leidecker, J. K.; Bruno, A. V. (1984). Identifying and using critical success factors. Long range planning, 17(1), pp. 23-32.

[28] Walport, M. (2016). Distributed ledger technology: beyond block chain. UK Government Office for Science, London. UK, Technical report.

[29] Guo, Y.; Liang, C. (2016). Blockchain application and outlook in the banking industry. Financial Innovation, 2(1), 24.

[30] Zavadskas, E. K.; Antucheviciene, J.; Vilutiene, T.; Adeli, H. (2018). Sustainable decision-making in civil engineering, construction and building technology. Sustainability, 10(1), 14 .

[31] Wind, Y.; Saaty, T. L. (1980). Marketing applications of the analytic hierarchy process. Management science, 26(7), pp. 641-658.

[32] Saaty, T. L.; Kearns, K. P. (2014). Analytical planning: The organization of system (Vol. 7). Elsevier.

[33] Kwiesielewicz, M.; Van Uden, E. (2004). Inconsistent and contradictory judgements in pairwise comparison method in the AHP. Computers \& Operations Research, 31(5), pp. 713-719.

[34] Vargas, L. G. (1982). Reciprocal matrices with random coefficients. Mathematical modelling, 3(1), pp. 69-81.

[35] Vinogradova, I.; Podvezko, V.; Zavadskas, E. K. (2018). The recalculation of the weights of criteria in MCDM methods using the bayes approach. Symmetry, 10(6), 205.

[36] Offutt, J.; Abdurazik, A. (1999). Generating tests from UML specifications. In International Conference on the Unified Modeling Language pp. 416-429. Springer, Berlin, Heidelberg. 